\title{
PENGONTROLAN BUKA TUTUP ATAP DAN BLOWER OTOMATIS UNTUK JEMURAN MENGGUNAKAN MIKROKONTROLLER ARDUINO UNO BERBASIS ANDROID
}

\author{
Asep Saefullah ${ }^{1}$ \\ Dewi Immaniar Desrianti ${ }^{2}$ \\ Mohamad Reza Kurniawan ${ }^{3}$ \\ Jl. Jendral Sudirman No. 40, Modernland, Tangerang \\ Email : asep.saepullah@raharja.info,dewi.immaniar@raharja.info, mohamadrezakurniawan@raharja.info
}

\begin{abstract}
ABSTRAK
Tujuan penelitian untuk memberikan nilai efisiensi terhadap kinerja dalam buka tutup atap dan blower pada jemuran pakaian yang ditunjukan kepada CV.Trideko Interior dan Eksterior adalah sebuah badan usaha yang bergerak dalam bidang interior dan eksterior design. Metodelogi yang digunakan adalah dalam menentukan permasalahan dipergunakan metode perancangan, metode prototype, dan metode testing. Untuk mengumpulkan data-data primer digunakan metode observasi dan wawancara. Dan untuk mendapatkan data-data sekunder digunakan metode pustaka terkait dengan teori-teori dasar untuk memperkuat dasar teoritis yang dipergunakan. Adapun dalam menghasilkan sebuah sistem alat kontrol buka tutup atap dan blower menggunakan metode perancangan flowchart. Manfaat penelitian secara khusus ditunjukan kepada CV.Trideko Interior dan Eksterior. Secara umum dari sistem alat kontrol yang di hasilkan bermanfaat terhadap kalagan masyarakat luas. Terhadap kinerja buka tutup atap dan blower untuk jemuran pakaian.
\end{abstract}

Kata kunci : kontrol, jemuran dan android

\begin{abstract}
The research objective to provide the efficiency of the performance in the opening and closing of the roof and blower on a clothesline clothing shown to CV.Trideko Interior and exterior is a business entity engaged in the field of interior and exterior design. Methodology used is the method used in determining the issues of designing, prototyping methods, and methods of testing. To collect the primary data used observation and interview methods. And to obtain secondary data used literature method associated with the basic theories to strengthen theoretical basis used. As for the tool generates a system control opening and closing of the roof and a blower using design methods flowchart. Benefits of research specifically indicated to CV.Trideko interior and exterior. In general system control device that produced kalagan beneficial to society at large. The performance of the opening and closing of the roof and a blower for washing clothes.
\end{abstract}

Keywords: control, clothesline and android

\section{PENDAHULUAN}

Menjemur pakaian adalah salah satu kegiatan yang sering dilakukan didalam kehidupan rumah tangga, dan biasanya menjemur pakaian sering kita tinggal berpergian, sehingga kita tidak sempat untuk mengangkat jemuran pada waktu akan turun hujan. Pemanasan global yang sekarang ini terjadi mengakibatkan cuaca yang sulit di tebak. Sehingga terjadi perubahan secara tiba-tiba dari panas menjadi hujan ataupun sebaliknya sehingga kegiatan menjemur pakaian menjadi terganggu. 
Sunlouvre adalah atap alumunium yang bisa dibuka dan ditutup, mengendalikan intensitas sinar matahari dan hujan. kontruksi sunlouvre dapat di gunakan untuk menjemur pakaian. Sehingga dengan adanya sunlouvre dapat membantu kegiatan menjemur pakaian. Namun dalam membuka dan menutup atap pada sunlouvre masih manual. Masih harus menarik tali sunlouvre untuk membuka atap dan menutup atap pada saat menjemur pakaian. dengan menarik tali sunlouvre untuk membuka dan menutup atap kegiatan menjemur pakaian tidak bisa di tinggal pergi.

Untuk mengatasi masalah tersebut perlu adanya pengembangan sistem kontrol otomatis. Dengan cara membuat pengembangan sistem buka tutup atap otomatis menggunakan smartphone. Dalam perancangan implementasi sistem buka tutup atap otomatis masalah masalah yang dipecahkan adalah meliputi sistem pengendali atap, arsitektur perangkat keras, perangkat elektronik dan mekanik dari keterangan diatas dipadukan untuk merealisasi sistem pengendalian buka tutup atap otomatis.

\section{RUMUSAN MASALAH}

Perubahan cuaca yang secara tiba - tiba terkadang menyebabkan kegiatan rumah tangga yaitu menjemur pakaian menjadi terganggu, sehingga perlu adanya sebuah alat yang dapat membantu mengatasi masalah rumah tangga tersebut.

Dalam hal ini maka penulis mencoba merancang sistem teknologi berdasarkan latar belakang kita dapat simpulkan beberapa permasalahan, yaitu :

Bagaimana mikrokontroler Arduino Uno dapat berinteraksi dengan smartphone android?

Bagaimana cara melakukan pengontrolan membuka dan menutup atap dengan mikrokontroler Arduino Uno?

Bagaimana interface dari smartphone android dapat mengendalikan atap sunlouvre?

\section{METODE PENELITIAN}

Pada saat ini terdapat banyak metodologi dalam pembangunan sistem. Salah satu metode pengerjaan yang akan digunakan dalam penelitian ini adalah metode prototype. Secara umum dalam pembangunan sistem yang ada pada prototype terdapat tahapan-tahapan sebagai berikut :

\section{a. Metode analisa kebutuhan}

Metode ini melakukan analisa suatu sistem yang sudah ada, bagaimana sistem itu berjalan dan apakah kekurangan dari sistem tersebut. Pada sistem yang ada pada penelitian penggunaannya masih secara manual, sehingga perlu adanya sistem yang dapat membantu pekerjaan rumah tangga khususnya dalam kegiatan menjemur pakaian.

\section{b. Metode perancangan sistem}

Dalam metode perancangan ini kita dapat mengetahui bagaimana sistem itu dibuat atau dirancang dan alat apa saja yang dibutuhkan. Melalui tahapan pembuatan flowchart dari sistem yang akan dibuat dan perancangan prototype.

c. Metode pengujian sistem

Pada metode pengujian ini yang dipakai adalah metode pengujian black box.

\section{LITERATURE REVIEW}

Salah satu penerapan dalam metode pengumpulan data dalam studi pustaka, studi pustaka bermanfaat agar menghindari pembuatan ulang, mengidentifikasi metode yang pernah dilakukan serta untuk mengetahui penelitian lain yang mempunyai area yang sama dalam bidang ini. Literature review merupakan suatu survey literature tentang penemuan-penemuan Vol.2 No.2 - Agustus 2016 
yang telah dilakukan oleh penelitian sebelumnya yang berhubungan dengan topic penelitian dalam upaya mengembangkan dan menyempurnakan. Diantaranya sebagai berikut :

1. Penelitian yang dilakukan oleh Reza Amar Juliansyah dari STMIK RAHARJA TANGERANG yang berjudul "Perancangan Sistem Kontrol Robot Pemindah Barang Menggunakan Aplikasi Android Berbasis Arduino Uno" tahun 2014, alat ini tentang pengontrolan robot pemindah barang menggunakan smartphone android dan arduino uno dengan menggunakan koneksi Bluetooth untuk meringankan pekerjaan manusia dalam hal pemindahan barang.

2. Penelitian yang dilakukan oleh Deinsyah Fakhrizal dari STMIK RAHARJA TANGERANG yang berjudul "Prototype Weather Berbasis Arduino Yun" Tahun 2014, alat ini dapat memantau kondisi cuaca pada lingkungan sekitar dengan output data parameter cuaca seperti kelembaban udara, suhu udara, intensitas cahaya, tekanan udara dan ketinggian setiap 1 jam sekali pda status jejaring social facebook.

3. Penelitian yang dilakukan oleh Ridwan Anas dari UNIVERSITAS DIPENEGORO SEMARANG yang berjudul "Rancang Bangun Prototype Buka Tutup Atap Otomatis Untuk Pengeringan Proses Produksi Berbasis Mikrokontroler AT89S51" tahun 2010, alat ini dapat membuka dan menutup atap secara otomatis menggunakan sensor LDR dan Mikrokontroler AT89S51 untuk proses produksi dengan penjemuran menggunakan menggunakan sinar matahari.

4. Penelitian yang dilakukan oleh Ma'ful Wahyu Nurhadi dan Paulinus Yunawan Widiantoro dari STMIK AMIKOM YOGYAKARTA yang berjudul "Jemuran Pakaian Otomatis Dengan Menggunakan Sensor Cahaya (Ldr) Dan Sensor Hujan” tahun 2010. Di mana sistem ini menggunakan ATMega8535 dan software yang digunakan Bascom AVR. Dan menggunakan LCD untuk tampilan serta sensor hujan. Sedangkan pada system jemuran pakaian otomatis tersebut menggunakan IC LM 741 sebagai penguat arus yang keluar dari sensor sehingga bias mengaktifkan relay.

5. Penelitian yang dilakukan oleh Chandra G. Munthe dan Manginar Pardosi dari POLITEKNIK NEGERI MEDAN yang berjudul "Rancang Bangun Jemuran Pakaian Otomatis Menggunakan Sensor Dan Kipas Angin Berbasis Mikrokontroler ATmega8535" pada tahun 2013. Di mana pada saat ingin menjemur pakaian cukup hanya dengan menekan tombol ON/OFF saja, jemuran akan bergerak keluar dari rumah dan ketika cuaca hujan jemuran pakaian akan bergerak masuk kerumah. Pada saat jemuran pakaian berada didalam rumah dua kipas akan membantu pengeringan pakaian. Hal ini dilakukan oleh sensor fotoelektrik yang mendeteksi ada pakaian dan tidak ada pakaian di jemuran. Sensor cahaya mendeteksi terang atau gelap di luar rumah dan sensor hujan mendeteksi hujan diluar rumah. Semua ini merupakan input pada mikrokontroler ATmega8535 sebagai pengendali.

Dari beberapa sumber literature review di atas, dapat diketahui bahwa penelitian tentang mikrokontroler, sensor-sensor dan pengontrolan secara otomatis sudah banyak dibahas. Tapi belum ada penelitian membuat pengontrolan jemuran dengan Smartphone Android. Maka dari itu dilakukannya penelitian untuk kemajuan teknologi yang sekarang ini sudah berkembang dengan pesat. Sehingga pengontrolan dapat dilakukan dengan menggunakan smartphone. Dewasa ini smartphone sudah banyak dipakai untuk berbagai macam kegiatan dan selalu dibawa kemana-mana, penggunaannya sangatlah mudah dan tidak terlalu rumit. Untuk itu dibuatlah penelitian yang berjudul "Pengontrolan Buka Tutup Atap Dan Blower Otomatis Untuk Jemuran Menggunakan Mikrokontroller Arduino Uno Berbasis Android" 


\section{PEMBAHASAN}

Agar mempermudah dalam menjelaskan perancangan perangkat keras, maka di gambarkan alur dan cara kerja perangkat keras pada rangkaian diagram blok pada gambar 1 di bawah ini

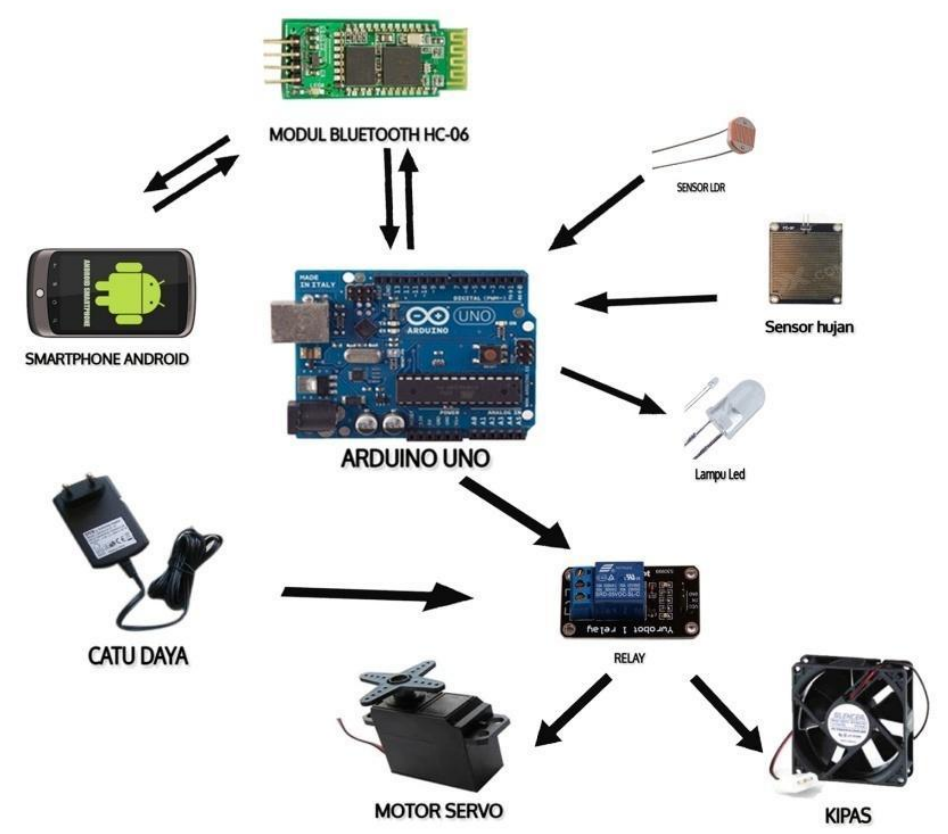

Gambar 1. Diagram Blok Rangkaian Sistem

Keterangan dan penjelasan Diagram Blok diatas adalah sebgai berikut :

1. Smartphone Android merupakan perangkat yang digunakan untuk menjalankan aplikasi yang berfungsi untuk mengendalikan atap dan blower melalui koneksi Bluetooth HC-06.

2. Modul Bluetooth HC-06 merupakan perangkat yang dapat menerima dan mengirim sinyal untuk komunikasi antara smartphone android dengan mikrokontroler Arduino Uno.

3. Aduino uno sebagai platform untuk memasukkan program ke dalam Mikrokontroler Atmega328 yang merupakan pusat pengontrolan yang terdapat program didalamnya.Arduino ini dapat berinteraksi dengan Smartphone melalui koneksi Bluetooth, Menerima sinyal dari sensor LDR dan sensor hujan

4. Sensor LDR merupakan sensor cahaya untuk memberi input kepada arduino uno tentang intensitas cahaya

5. Sensor hujan merupakan sensor pendeteksi air pada saat turun hujan.

6. Lampu Led sebagai indicator power dan indicator cuaca.

7. Power Supply merupakan catu daya untuk memberikan tegangan kepada arduino uno

8. Blower/kipas merupakan perangkat yang digunakan untuk membantu mengeringkan pakaian pada saat atap tertutup.

9. Motor Servo menggerakan atap agar atap terbuka dan tertutup.

10. Relay sebagai switch atau saklar untuk blower/kipas.

\section{FLOWCHART SISTEM}

Dalam pembuatan sistem dan perancangan program dapat digambarkan dalam bentuk flowchart sehingga dapat mempermudah dalam melakukan dan merancang langkah-langkah 
atau proses dengan benar. Adapun bentuk dari flowchart keseluruhan dari sistem yang dibuat dapat dilihat pada gambar berikut.

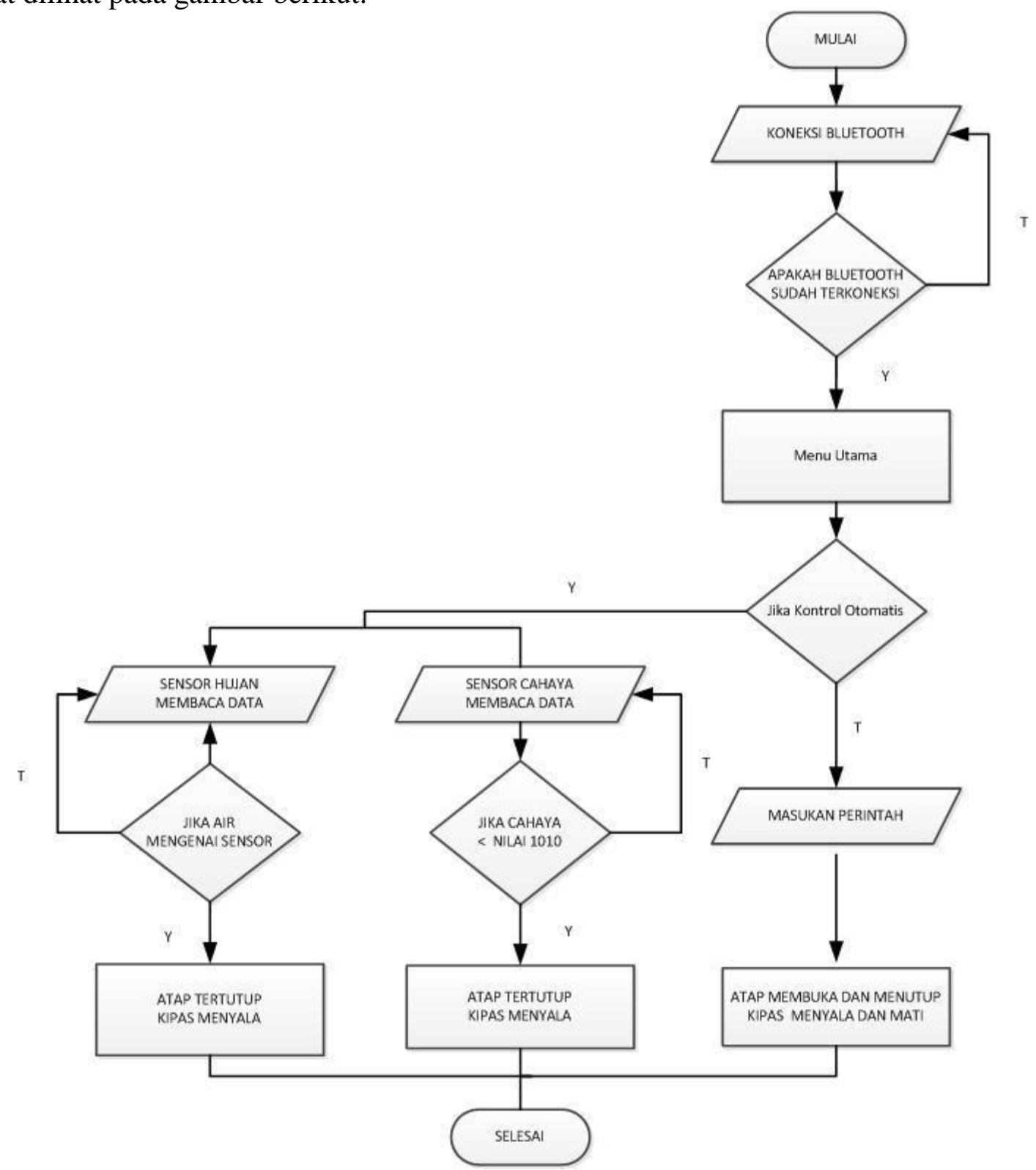

Gambar 2. Flowchart sistem yang di usulkan

\section{RANCANGAN PROTOTYPE}

Prototipe pengontrolan atap dan blower otomatis untuk jemuran menggunakan mikrokontroller arduino uno berbasis android ini perancangan prototype disusun dengan menggunakan bahan kayu dan sterofom sebagai bahan prototype, dalam alat ini juga dilengkapi dengan komponen seperti : smartphone untuk mengontrol atap , arduino uno, Bluetooth HC-06, sensor LDR, sensor hujan dan servo yang dijadikan sebagai penggerak atap untuk mendukung kinerja alat tersebut. 


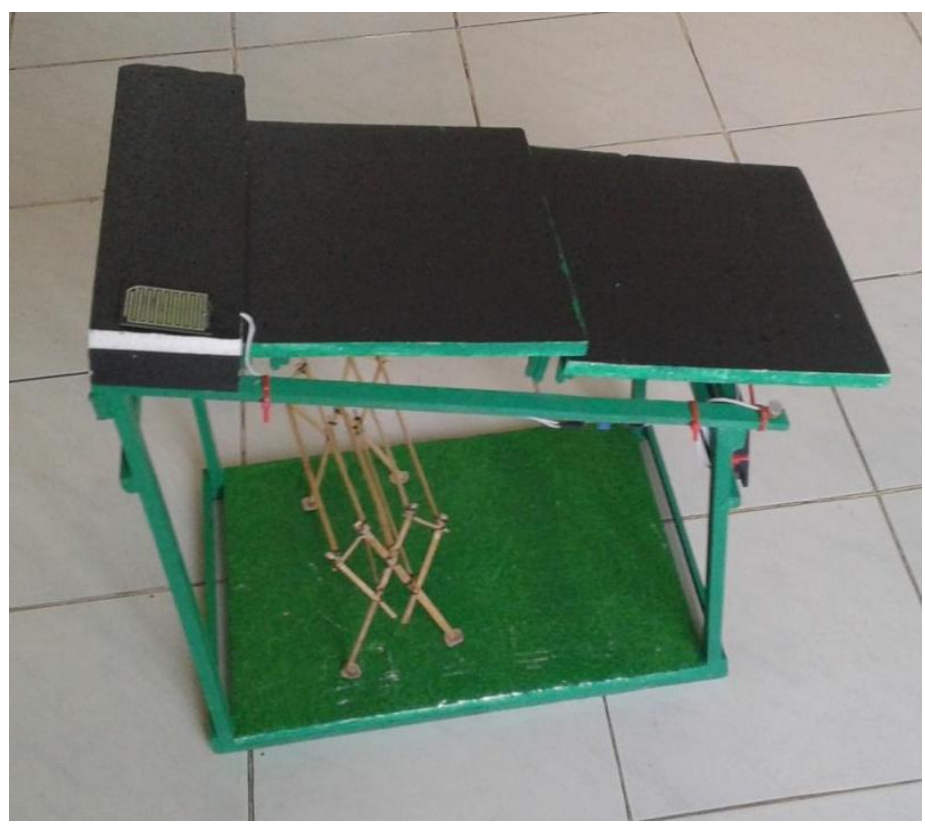

Gambar 3. Prototype

\section{Analisa Program Pada Mikrokontroller}

penulisan listing program diawali dengan kode:

\#include <Servo.h>

Kode di atas merupakan fungsi libraries yang ada pada software Arduino yang didalamnya terdapat fungsi-fungsi yang untuk digunakan pada motor servo.

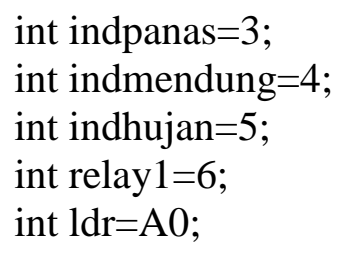

Kode di atas merupakan fungsi untuk mendeklarasikan atau penamaan terhadap variabel komponen yang digunakan, sedangkan barisan kode yang digunakan sebagai fungsi sensor dan motor servo dapat dilihat pada baris program berikut ini.

const int sensorMin $=0$;

const int sensorMax $=1024$;

int val $=0$;

int $\operatorname{pos} 1=10$;

int $\operatorname{pos} 2=45$;

int $\operatorname{pos} 3=140$;

int $\operatorname{pos} 4=10$;

int pos $5=45$;

int $\operatorname{pos} 6=140$;

Sedangkan program yang digunakan untuk melakukan perintah-perintah eksekusi baik berupa input ataupun output dapat dilihat pada blok void setup. Pada bagian ini program akan 
dialamatkan sebagai media output dan input tergantung pada penggunaan dari device-device yang terhubung.

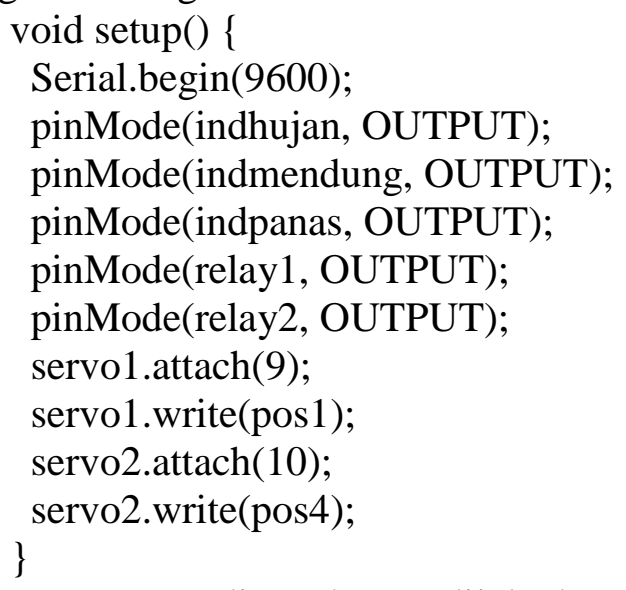

Program diatas hanya dijalankan selama sekali ketika pada saat pertama kali system mendapat arus listrik, sedangkan program yang dapat berjalan berulang kali akan terlihat seperti baris program berikut ini.

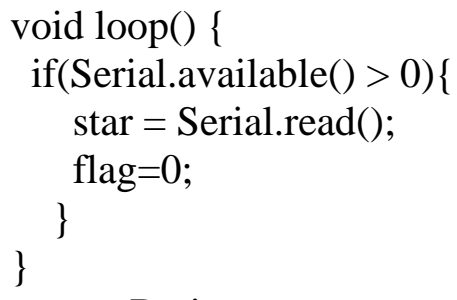

Barisan program arduino yang ada diatas akan dijalankan berulang kali selama arus listrik mengalir pada arduino.

\section{UJI COBA DAN IMPLEMENTASI}

\section{UJI COBA}

Setelah melakukan berbagai tahapan perancangan dan pemasangan komponen, selanjutnya adalah melakukan serangkaian uji coba pada masing-masing blok rangkaian yang bertujuan untuk mendapatkan hasil yang sesuai. Tujuan dari pengujian ini adalah proses komunikasi data antara aplikasi dengan atap dan blower yang akan dikendalikan melalui perangkat Bluetooth sebagai media komunikasi. Hasil pengujian dilakukan menggunakan metode black box, bisa dilihat pada tabel berikut :

\begin{tabular}{|c|c|c|c|}
\hline \multirow[t]{4}{*}{ No } & Nama Form & Kondisi Pengujian & Hasil Pengujian \\
\hline & Motor Servo & Dikirim Logika 1-255 & Servo Bergerak 1-180 \\
\hline & & Dikirimkan Logika 0 & Servo Tidak Bergerak \\
\hline & Modul Bluetooth & \begin{tabular}{lrll}
\multicolumn{2}{l}{ Menghubungkan } & PIN & RX \\
Bluetooth & Ke & Pin & Rx \\
Arduino & Dan & Pin & Tx \\
Bluetooth & Ke & Pin & Tx
\end{tabular} & $\begin{array}{ll}\text { Device } & \text { Bluetooth } \\
\text { Tidak } & \text { Menerima } \\
\text { Perintah } & \end{array}$ \\
\hline
\end{tabular}




\begin{tabular}{|c|c|c|}
\hline & Arduino & \\
\hline & \begin{tabular}{lrrr}
\multicolumn{2}{l}{ Menghubungkan } & PIN & RX \\
Bluetooth & Ke & Pin & Tx \\
Arduino & Dan & Pin & Tx \\
Bluetooth & Ke & Pin & Rx \\
Arduino & & &
\end{tabular} & $\begin{array}{l}\text { Modul Bluetooth } \\
\text { Dapat Diperintah / } \\
\text { Modul Bluetooth Siap } \\
\text { Menerima Perintah }\end{array}$ \\
\hline Aplikasi Android & $\begin{array}{l}\text { Aktifkan Bluetooth Dan } \\
\text { Scanning Perangkat Modul } \\
\text { Bluetooth }\end{array}$ & Modul Bluetooth Aktif \\
\hline & $\begin{array}{l}\text { Tidak Melakukan Scanning } \\
\text { Perangkat Modul Bluetooth }\end{array}$ & Modul Tidak Aktif \\
\hline Sensor Hujan & $\begin{array}{l}\text { Ketika Sensor Hujan Tidak } \\
\text { Terkena Tetesan Air }\end{array}$ & Nilai Output Rendah \\
\hline & $\begin{array}{lcc}\text { Ketika Sensor } & \text { Hujan } \\
\text { Terkena Tetesan Air } & \end{array}$ & $\begin{array}{l}\text { Nilai Output Kembali } \\
\text { Tinggi }\end{array}$ \\
\hline Sensor LDR (Cahaya) & $\begin{array}{l}\text { Ketika Sensor Ldr Terkena } \\
\text { Cahaya }\end{array}$ & $\begin{array}{l}\text { Nilai Resistansinya } \\
\text { Berubah }\end{array}$ \\
\hline
\end{tabular}

Tabel 1. Metode blackbox perangkat keras

\begin{tabular}{|c|c|c|c|c|}
\hline No & Nama Pengujian & Hasil Yang Diharapkan & Hasil Pengujian & Status \\
\hline & $\begin{array}{lr}\text { Connect } & \text { Bluetooth } \\
\text { Dari } & \text { Aplikasi } \\
\text { Dengan Bener }\end{array}$ & $\begin{array}{lr}\text { Mencari } & \text { Device } \\
\text { Bluetooth } & \text { Sesuai } \\
\text { Dengan Tipe } & \text { Bluetooth } \\
\text { Modul HC-06 } & \end{array}$ & $\begin{array}{l}\text { Setelah Connect } \\
\text { Maka Lampu Pada } \\
\text { Bluetooth Modul } \\
\text { Akan Menyala }\end{array}$ & Diterima \\
\hline & $\begin{array}{lr}\text { Connect } & \text { Bluetooth } \\
\text { Dari } & \text { Aplikasi } \\
\text { Dengan Salah }\end{array}$ & $\begin{array}{lr}\text { Mencari } & \text { Device } \\
\text { Bluetooth } & \text { Sesuai } \\
\text { Dengan Tipe } & \text { Bluetooth } \\
\text { Modul Hc-06 } & \end{array}$ & $\begin{array}{ll}\text { Bluetooth } & \text { Tidak } \\
\text { Ada Respon } & \end{array}$ & Ditolak \\
\hline & Input "A" & $\begin{array}{lrrr}\text { Servo } 1 & \text { Dan } & \text { Servo } 2 \\
\text { Berputar } & 110^{\circ} & \text { Dari Kiri } \\
\text { Ke Kanan } & \text { Atau } \\
\text { Sebaliknya } & & \end{array}$ & $\begin{array}{l}\text { Maka Outputnya } \\
\text { Atap Akan Terbuka }\end{array}$ & Diterima \\
\hline & Input "B" & Servo 1 Dan Servo 2 & Outputnya & Diterima \\
\hline
\end{tabular}




\begin{tabular}{|c|c|c|c|}
\hline & $\begin{array}{l}\text { Berputar } 90^{\circ} \text { Dari Kiri } \\
\text { Ke Kanan Atau } \\
\text { Sebaliknya }\end{array}$ & $\begin{array}{l}\text { Akan Atap Akan } \\
\text { Terbuka } \\
\text { Sepenuhnya }\end{array}$ & \\
\hline Input 'C" & $\begin{array}{lrr}\text { Servo 1 Dan } & \text { Servo } 2 \\
\text { Berputar } 125^{\circ} \text { Dari Kiri } \\
\text { Ke Kanan } & \text { Atau } \\
\text { Sebaliknya } & \end{array}$ & $\begin{array}{l}\text { Maka Outputnya } \\
\text { Akan Atap Akan } \\
\text { Tertutup } \\
\text { Sepenuhnya }\end{array}$ & Diterima \\
\hline Input "D" & $\begin{array}{l}\text { Relay Hidup Untuk } \\
\text { Menggerakan Kipas }\end{array}$ & $\begin{array}{lr}\text { Maka } & \text { Outputnya } \\
\text { Kipas } & \text { Akan } \\
\text { Menyala } & \end{array}$ & Diterima \\
\hline Input "E" & $\begin{array}{ll}\text { Relay Mati } & \text { Untuk } \\
\text { Membuat } & \text { Kipas } \\
\text { Berhenti } & \\
& \end{array}$ & $\begin{array}{l}\text { Maka Outputnya } \\
\text { Kipas Berhenti }\end{array}$ & Diterima \\
\hline Input "F" & $\begin{array}{lrr}\text { Sensor Hujan } & \text { Dan } \\
\text { Sensor Ldr Aktif } & \end{array}$ & $\begin{array}{l}\text { Maka Outputnya } \\
\text { Kedua Sensor Aktif }\end{array}$ & Diterima \\
\hline
\end{tabular}

Tabel 2. Metode blackbox perangkat lunak

\section{IMPLEMENTASI}

Setelah melakukan Uji coba alat, selanjutnya implementasi sistem. Kebutuhan aplikasi sistem pengontrolan yang akan diimplementasikan sebagai berikut :

Kebutuhan aplikasi :

1 buah smartphone berbasis android, minimal andoid versi 4.0 ICS (Ice Cream Sandwich)

Kebutuhan Prototype :

1. Modul Bluetooth HC-06 : merupakan perangkat yang dapat menerima dan mengirim sinyal untuk komunikasi antara smartphone android dengan mikrokontroler Arduino Uno.

2. Aduino uno : sebagai platform untuk memasukkan program ke dalam Mikrokontroler Atmega328 yang merupakan pusat pengontrolan yang terdapat program didalamnya.Arduino ini dapat berinteraksi dengan Smartphone melalui koneksi Bluetooth, Menerima sinyal dari sensor LDR dan sensor hujan

3. Sensor LDR : merupakan sensor cahaya untuk memberi input kepada arduino uno tentang intensitas cahaya

4. Sensor hujan : merupakan sensor pendeteksi air pada saat turun hujan.

5. Motor Servo : menggerakan atap agar atap terbuka dan tertutup.

6. Relay : sebagai switch atau saklar untuk blower/kipas.

Aplikasi android memiliki beberapa fungsi :

1. Scaning Bluetooth, mencari perangkat Bluetooth yang sedang aktif disekitar peangkat

2. Mengontrol atap dan blower secara manual maupun secara otomatis pada aplikasi 
android.

Aplikasi dipasang pada smartphone yang berbasis android dalam penelitian ini menggunakan smartphone android versi jellybean. Aplikasi yang dibuat dapat berkomunikasi dengan atap dan blower menggunakan koneksi Bluetooth. untuk membuka dan menutup atap. Pada sistem ini menggunakan modul bluetooth hc-06, smartphone android dapat mengontrol atap dengan menggunakan modul Bluetooth hc-06.lalu selanjutnya akan di eksekusi oleh mikrokontroller.

\section{KESIMPULAN}

Dari perancangan yang dilakukan dapat diperoleh kesimpulan sebagi berikut :

1. Smartphone Android dapat berinteraksi dengan arduino uno menggunakan koneksi Bluetooth sebagai alat interaksinya. pada alat ini menggunakan Bluetooth HC-06.

2. Cara membuka tutup atap otomatis dengan mikrokontroler arduino yaitu dengan menggunakan bantuan motor servo yang bergerak agar atap dapat terbuka dan tertutup.

3. Pada smartphone android harus terinstal aplikasi Bluetooth terminal, agar atap sounlover dapat dikendalikan melalui smartphone android.

\section{DAFTAR PUSTAKA}

[1] Muntheda,Chandra G. Dan Mangina. 2013. "Rancang Bangun Jemuran Pakaian Otomatis Menggunakan Sensor Dan Kipas Angin Berbasis Mikrokontroler Atmega8535".Politeknik Negeri Medan. Medan (31 Agustus)

[2] Anas, Ridwan. 2010."Rancang Bangun Prototipe Buka Tutup Atap Otomatis Untuk Pengeringan Proses Produksi Berbasis Mikrokontroler AT89S51".Universitas Dipenegoro. Semarang.

[3] Nurhadi, Ma'ful Wahyu. Dan Paulinus Yunawan Widiantoro. 2010."Jemuran Pakaian Otomatis Dengan Menggunakan Sensor Cahaya (Ldr) Dan Sensor Hujan".STMIK Amikom Yogyakarta

[4] Juliansyah, Reza Amzu. 2014. Sistem kontrol robot pemindah barang menggunakan aplikasi android berbasis arduino uno" Jurusan Sistem Komputer, SKRIPSI, STMIK Raharja.

[5] Fakhrizal, deinsyah. 2014. "prototype weather station berbasis arduino yun." Jurusan Sistem Komputer, SKRIPSI, STMIK Raharja. 